\title{
LICHENOMETRY ON ADELAIDE ISLAND, ANTARCTIC PENINSULA: \\ SIZE-FREQUENCY STUDIES, GROWTH RATES AND SNOWPATCHES
}

\author{
BY \\ GOLLEDGE, N.R ${ }^{1,2}$, EVEREST, J.D. ${ }^{1}$, BRADWELL, T. ${ }^{1}$ \& JOHNSON, J.S. ${ }^{3}$ \\ ${ }^{1}$ British Geological Survey, Murchison House, Edinburgh, UK \\ ${ }^{2}$ Antarctic Research Centre, Victoria University of Wellington, New Zealand \\ ${ }^{3}$ British Antarctic Survey, Cambridge, UK
}

Golledge, N.R., Everest, J.D., Bradwell, T. and Johnson, J.S., 2010: Lichenometry on Adelaide Island, Antarctic Peninsula: size-frequency studies, growth rates and snowpatches. Geogr. Ann., 92A: xx-xx.

\begin{abstract}
This paper presents new lichenometric population data from the Antarctic Peninsula (67\% $)$, and describes a new approach to lichen growth-rate calibration in locations where dated surfaces are extremely rare. We use historical aerial photography and field surveys to identify sites of former perennial snowpatches where lichen populations now exist. As an independent check on lichen mortality by snowkill, and the timing of snow patch disappearance, we use a positive-degree day (PDD) approach based on monthly climate data from Rothera Research Station. We find that maximum growth rates for lichens $<40 \mathrm{~mm}$ in diameter on Adelaide Island are around $0.8 \mathrm{~mm} / \mathrm{yr}$. Furthermore, we propose that our combined methodology may be more widely applicable to the Polar regions where the construction of lichenometric dating (age-size) curves remains a problem.
\end{abstract}

Key words: glaciation, snow patches, Rhizocarpon, positive degree day, photogrammetry

\section{Introduction}

Lichenometric dating is a valuable dating tool for geoscientists. The combination of extremely slow growth in certain species together with their common occurrence in widely ranging environments has been a key factor in most lichenometric dating studies. Knowledge of a species' growth rate can be used to determine surface-exposure ages spanning the past five centuries in some, more arid, settings (e.g. Beschel 1961; Karlén and Black 2002; Solomina and Calkin 2003). Most lichenometric dating studies have focused on the yellow-green Rhizocarpon Ram. em Th. Fr. subgenus Rhizocarpon (Poelt 1988).

Despite the numerous studies utilising the growth rate of lichens worldwide (see reviews by Innes, 1985; Noller and Locke 2001; Bradwell and Armstrong 2007), very few lichenometric dating studies have been attempted on sub-Antarctic islands - Birkenmajer (1981) being one of the few; and to the authors’ knowledge no lichenometric dating studies have been reported from continental Antarctica. A 
number of monitoring studies have investigated the growth rates of crustose lichens in Antarctica and the lichen colonization of recently exposed surfaces (e.g. Hooker 1980; Kappen and Breuer 1991; Lewis Smith 1995; Valladares and Sancho 1995; Sancho and Pintado 2004; Sancho et al. 2007) - but, as yet, these measurement data have not been used for geochronological purposes.

Given this relative lack of lichenometric studies (geochronological or ecological) in the Antarctic Peninsula region, the aims of this study were twofold: 1) to establish a robust technique for lichen growth rate calibration in areas where surfaces of known age are largely absent, and 2) to apply this calibration technique to a number of lichen sites across Ryder Bay, Adelaide Island, to establish minimum ages for glacier ice or permanent snowpatch disappearance on a decadal to centennial scale. We present size-frequency distribution and maximum-size data of yellow-green Rhizocarpon lichens growing on recently exposed surfaces in Ryder Bay, Adelaide Island (Figure 1), and, by inference, make an assessment of lichen growth rates over the past three decades on this part of the Antarctic Peninsula. We propose a novel technique for establishing surface exposure ages from lichens in locations where age calibration is limited or absent, and briefly discuss the wider implications of the lichenometric technique in polar settings.

\section{Lichens and snow cover}

Pitman (1973) noticed that lichen diameters in west Greenland increased with distance away from semi-permanent snowpatches. A similar phenomenon has since been noted in the Colorado Rocky Mountains and Arctic Canada (e.g. Koerner 1980; Benedict 1990; Levesque and Svoboda 1995). Benedict $(1990,1991)$ has studied the relationship between crustose lichens and snow cover intimately. He has shown that in certain situations lichen growth is considerably hampered by persistent snow and can result in mortality once a threshold is crossed. This relationship has now been demonstrated in a number of different environments. In Colorado, for example, monitoring over many years has shown that yellow-green Rhizocarpon lichens require a snow-free window of at least 10-12 weeks a year in order to survive (Benedict 1990, 1991). In southeast Iceland, a maritime subpolar setting where lichen growth is more rapid, year-long snowlie for only 2 successive years was found to have caused death and disappearance in more than 95\% of Rhizocarpon thalli monitored (Bradwell, 2001b). Modelling studies of lichen populations in northern Iceland were similarly found to most closely match field observation when snowkill events, based on a snow-free window of 12 weeks or less, were introduced (Caseldine and Baker, 1998).

Benedict (1990) found that species resistance to snowkill is inversely related to growth rate. Fastergrowing lichens are less able to withstand periods of snow cover probably because they metabolise more rapidly and thus require longer photosynthesis windows to redress the balance (Benedict, 1990). Other lichenologists have reported an increase in species diversity with distance away from large snow patches, and also the tendency of some hardy alpine 'specialists' to favour the ecological niches provided by late-lying or semi-permanent snow (e.g. Gilbert et al. 1992; Fryday 2001). 
The general consensus of the ecological studies described above is that the relative lack of lichens within relict or ephemeral snow patches is probably due to unfavourable micro-environmental conditions - such as reduced light intensities, intolerably high moisture and humidity levels (e.g. Kershaw 1985; Fryday 2001). Partial melting of snow patch margins in the summer reveals a zone of ground that is only available for lichen colonisation during the (high) summer months, (typically. 8-12 weeks) each year. This brief 'growing season' may not be long enough to guarantee the survival of even the hardiest lichen flora, hence the presence of lichen free ground. Lichen-free areas and lichen 'trim-lines' are therefore thought to be contemporary features reflecting the recent ( $20^{\text {th }}$ century) distribution of late-lying snow. Importantly in the context of this study, Rhizocarpon geographicum, is a chionophobic lichen species (i.e. it avoids snow-covered areas), and its absence from rocks within late-lying snow patches has been demonstrated by detailed taxonomic studies elsewhere (e.g. Mark and Bliss 1970; Fryday 1997, 2001).

Although lichen snowkill rates are currently unknown for the Antarctic Peninsula, analogy with environments described above indicates that in maritime subpolar settings (e.g. Adelaide Island), where lichen growth is relatively rapid $\left(>0.2 \mathrm{~mm} \mathrm{a}^{-1}\right)$, only a year or two of prolonged snow cover $(<12$ weeks effective exposure) may be sufficient to kill Rhizocarpon lichens and ensure that surfaces are free of thalli. Re-colonisation of these surfaces is therefore effectively 'primary', allowing for relatively robust estimates to be made of lichen growth rates, with no inherited thalli from previous periods of exposure.

\section{Ryder Bay, Adelaide Island}

Ryder Bay (Figure 2) is situated at 67³2’30” - 67³7’30”S on the eastern coast of Adelaide Island, western Antarctic Peninsula. The bay is bounded to the west by the peaks of Mt Gaudry (2565 m) and Mt. Liotard (2225 m), from which the Sheldon, Hurley and Turner Glaciers drain into the bay. To the north, Reptile Ridge (426 m) and Stork Ridge $(515 \mathrm{~m})$ separate the bay from the Wormald Ice Piedmont. Within Ryder Bay are a group of several islands, of which Anchorage (54 m), Leonie (502 $\mathrm{m}$ ), and Lagoon (49 m) are the largest. At the south-eastern end of Reptile Ridge, Rothera Point supports Rothera Research Station, the British Antarctic Survey’s principal logistics centre for BAS Antarctic field science.

Relatively little is known about the recent (decadal to millennial) palaeoenvironmental history of Ryder Bay. Since detailed climate records only began at Rothera in 1977, inferences about local climate prior to this date have to be made from regional records or from coarse-grid General Circulation Model reconstructions (e.g. Ingólfsson and Hjort 2002; Otto-Bliesner et al. 2006). Early Holocene (> 6 ka BP) data for the area are fragmentary, with studies principally focussed on establishing minimum ages of marine beach formation in Ryder Bay. Such studies suggest that beaches on Lagoon Island and Anchorage Island were formed around $4980 \pm 140{ }^{14} \mathrm{C}$ BP and $4310 \pm 40{ }^{14} \mathrm{C}$ BP respectively (Bentley et al. 2005), indicating that deglaciation of the Ryder Bay area occurred at least 5000 years ago. 


\section{Study Sites:}

Rothera Point The NE-SW aligned granodiorite ridge of Rothera Point is $37 \mathrm{~m}$ above sea level (a.s.l.) at its highest point, and is connected to the rest of Adelaide Island by a narrow isthmus (Fig. 3a). Six sites were investigated on Rothera Point, three at the southern end of the island, two in the north and one on the highest, central, point.

Anchorage Island Anchorage Island lies approximately $3.5 \mathrm{~km} \mathrm{SW}$ of Rothera Point in Ryder Bay (Fig. 3b), and is characterised by a central axial granodiorite ridge that is $54 \mathrm{~m}$ a.s.l. at its highest point. Two adjacent sites were investigated, at $37 \mathrm{~m}$ and $35 \mathrm{~m}$ a.s.l. The higher site was located within an area of clean, bare, bedrock that exhibited only very limited lichen colonisation, whereas rock surfaces at the second site were more considerably densely lichen covered.

Leonie Island Leonie Island is dominated by a steep peak rising to $502 \mathrm{~m}$ a.s.l., and lies approximately $2.5 \mathrm{~km}$ south of the calving margin of the Turner Glacier (Fig. 3c). Lichen thalli were measured on a series of granodiorite benches at 4,8 and $16 \mathrm{~m}$ a.s.l. on the northern flank of the island.

Lagoon Island On western Lagoon Island, 4 km SW of Rothera Point in the middle of Ryder Bay (Fig. 3d), two sites were investigated, both at $16 \mathrm{~m}$ a.s.l. At the first site, lichens were measured on a raised beach (cf. Bentley et al. 2005) composed of granodiorite clasts. The second series of lichen measurements were made on granodiorite bedrock immediately adjacent to the raised beach.

\section{Methods}

During February 2008 approximately 100 yellow-green Rhizocarpon lichens were measured at 13 sites around Ryder Bay - on Rothera Point, Anchorage, Leonie and Lagoon Islands. All lichen measurements were of the longest axis and surveys were typically conducted within areas less than 20 $\mathrm{m}^{2}$. Owing to the difficulties surrounding field identification to the species level, thalli were only broadly identified to the subgenus level, using the criteria of Poelt (1988) and identification guide of Øvstedal and Lewis Smith (2001). This subgenus incorporates Rhizocarpon section Rhizocarpon (formerly known as the Geographicum group (Runemark 1956)) which includes the species Rhizocarpon geographicum (L.) DC. (Cernohorský 1977), but also includes lichens belonging to the Alpicola section (=groups). Species within the Alpicola group usually colonize later but grow more rapidly than species within the Rhizocarpon group (Innes, 1983, 1985). As Rhizocarpon geographicum is an early colonizer within the subgenus, and all our study surfaces are relatively young ( $<100$ years) problems relating to differential growth rates (R. geographicum vs. $R$. alpicola) are probably negated. Notwithstanding these comments, field identification to the subgenus level was problematic in some instances and incorporation of similar looking yellow-green crustose lichens, such as Lecanora physciella, cannot be discounted. All measurements were made to the nearest millimetre using digital calipers, and all lichens measured were growing on granodioritic rocks. Elongate and misshapen thalli were included in the survey; coalescent thalli were not. 
Following established procedures (e.g. Bradwell, 2001a, 2004), lichen population size-frequency data were plotted using a class-size of $3 \mathrm{~mm}$ with the logarithm (base 10) of the frequency (expressed as a percentage) as the dependent variable, and the lichen diameter ( $\mathrm{mm}$ ) as the independent variable (Figure 6). Lichens falling below the modal class in each population were omitted from the graphical plots. Linear regression analyses were calculated, using the least-squares regression method; this enabled each size-frequency distribution to be described in the form $y=m x+c$.

No surfaces of known age on Rothera Point or the wider Ryder Bay area were found supporting Rhizocarpon lichens, thus precluding absolute dating control. In order to constrain the growth rate of yellow-green Rhizocarpon in our study area, therefore, we devised a methodology that made use of field survey and historical aerial photographs to bracket the age of lichen populations as closely as possible. Firstly, areas were identified during field survey where snow-kill had left patches of bare rock with little or no lichen colonisation, within or adjacent to rock surfaces with well established lichen communities. Site locations were recorded with a handheld Garmin GPS to a nominal accuracy of \pm 5 $\mathrm{m}(\mathrm{x}, \mathrm{y})$. We then located our sample sites in both the temporal and spatial context of former and extant perennial snowpatches by using a methodology similar to that of Fox and Cooper (1998), who used sequential sets of historical aerial photographs to establish the pattern and timing of snowpatch decline in Ryder Bay.

Despite long time gaps between their aerial photography runs (19, 13, 8 and 8 years), Fox and Cooper (1998) were able to demonstrate a clear pattern of snowpatch decline over the period 1957 - 1997 (Figure 4). For our lichenometric study, a more recent aerial photograph survey (2004) was also used. Using the GPS coordinates from field survey together with the georectified aerial imagery, changes in the extent of perennial snowpatches at each of our sample sites were temporally constrained to within the time period separating successive photograph runs. Based on the timing of snowpatch disappearance (or contraction) interpreted from the dates of the aerial photograph surveys (Table 1), lichen size-frequency (population) measurements from each site were used to derive an envelope of possible growth rates. This range of growth rates was then applied to lichens growing in areas outside the former snowpatches in order to calculate the likely range of maximum lichen population ages, and by inference, minimum surface exposure ages.

Given the uncertainties in the chronological control afforded by the aerial photography, we employed a second method as an independent check on our growth rate calculations. We used mean monthly air temperature data from Rothera Research Station, spanning the period 1977-2007, to calculate the total number of positive degrees per year, for each year of the records (Figure 5). Positive Degree-Day (PDD) totals are commonly used to calculate the melt component of glacier mass balance models (e.g. Braithwaite 1980, 1984) and, despite the many assumptions implicit in their derivations, degree-day totals are considered sufficiently reliable to accurately calculate integrated annual melt totals in sophisticated numerical ice-sheet models (e.g. Hubbard et al. 2009; Pollard and DeConto 2009). The PDD method is based on statistical relationships between air temperature and the melting of snow over 
time periods of several years. Here we apply the method at a monthly to annual scale, and whilst accepting that the statistical relationship may be less valid over such short timescales, we propose that use of the PDD technique is justified on the basis that full energy-balance data are not available, and thus the PDD gives the best available approximation of 'felt' climate.

By integrating the effects of sometimes widely ranging temperatures throughout the annual cycle, the PDD approach is able to better characterise annual climatic conditions than, for example, the annual mean temperature, which is susceptible to skewing by individual outliers, or individual summer maximums that could be unrepresentative of the rest of the year. Empirical studies have demonstrated a close relationship between positive degrees experienced by a snow surface and the amount of snowmelt that occurs, typically in the range $3-5 \mathrm{~mm} /{ }^{\circ} \mathrm{C}$ (Braithwaite and Olsen 1984; Singh et al. 2000). Thus, by employing a suitable coefficient, it is possible to estimate the amount of snow-melt in an area if the annual climatic history of an area is known. Given that lichen-kill is likely to result from the prolonged survival of a snowpack as a consequence of the limited summer melting of winter snowfall, interannual changes in degree-day totals may reasonably be expected to correlate closely with survival potential of lichen populations. A complication arises, however, in that changes in annual precipitation totals, as well as differences resulting from re-distribution of snow by wind, may modulate the effects of temperature conditions, such that the relationship between total degree days and snowpack depletion becomes less clear. These uncertainties notwithstanding, we assumed that the PDD method could be used to identify the most likely years when snowcover may have been sufficiently prolonged to bring about lichen mortality.

\section{Results and interpretation}

Size-frequency plots of yellow-green Rhizocarpon lichens from sites around Ryder Bay, Antarctic Peninsula (Figure 6) show several trends. Ten of the 13 sites contain coherent, single, unimodal populations with typical log-normal distribution patterns, whereas two (or possibly three) of the 13 sites (Anchorage Island 2 and Rothera Point (south) 3) display complex lichen distributions. These may imply compound, multiple populations or inherited thalli. When plotted as $\log _{10}$ frequency vs lichen size, these two datasets significantly deviate from a linear relationship, with $\mathrm{r}^{2}$ values of 0.82 and 0.73 respectively. At Anchorage Island 2, a much stronger correlation co-efficient is produced when the largest thallus $(65 \mathrm{~mm})$ is omitted from the regression. One of the benefits of the size-frequency technique is that it allows the identification of anomalously large thalli (Benedict 1967, 1985; Innes 1985). The Rothera Point (south) 3 dataset appears to display 2 discrete populations $(<25 \mathrm{~mm}$ and $>$ $25 \mathrm{~mm}$ thalli). The compound population suggests inheritance of pre-existing thalli at the study site. A further site Leonie Island (highest), displays complexity, which although not represented in its $r^{2}$ value (0.89), is manifest in its bimodal distribution (10 and $25 \mathrm{~mm}$ peaks). Other apparent complexity in the lichen populations (e.g. Rothera Point - bedrock, Rothera Point - middle) is probably a function of the relatively small sample sizes. At most sites only c. 100 thalli, rather than the normal 250-500 or more (cf. Benedict 1985, 2008; Caseldine 1991; Bradwell 2004), were measured owing to the small size of 
the snowpatch sites and the immaturity of the lichen populations. However, the datasets are nonetheless sufficiently large and coherent to allow robust lichenometric interpretations.

From the interpretation of aerial photographs we have been able to identify the timing of disappearance or recession of permanent snowpatches at three sites in the Ryder Bay area, Anchorage 1, Rothera 2 and Rothera 3. The uncertainties associated with these interpretations range from $13-19$ years. Based on our measurements of lichen populations at these sites we plot linear trendlines through mean age values that yield functions which in all cases explain $>90 \%$ of data variance. Figure 7 a illustrates linear regression trendlines based on the single largest, mean of the five largest, and mean of the ten largest lichens as functions of age (using the median of the time span of the aerial imagery). Error bars describe the uncertainties related to the latter. Guided by previous studies (e.g. Matthews 1975, 2005; Bull and Brandon 1998; Bradwell 2001a) we use the regression equation of the single largest lichen age-model $(y=0.788 x)$ to calculate ages for the remainder of the sites in our study, where direct age constraint was lacking (Figure 7b). We have attempted to quantify the likely age-envelope for larger lichens by presenting curves that incorporate reductions in growth rate of $10-30 \%$ for thalli $>40 \mathrm{~mm}$ in diameter (see Bradwell and Armstrong 2007). From these curves we propose that the largest lichens recorded in our study may be 80 - 100 years old.

\section{Positive degree-day model}

Monthly temperatures from Rothera spanning the period 1977 - 2007 enable the recent climate of the area to be characterised (Figure 5). The data show a declining trend in annual temperature range over the 30-year period, dominated principally by rising winter temperatures. Mean summer temperatures, although variable, appear to have remained largely constant. In order to investigate the relationship between temperature regime and lichen snow-kill, we compared three climatic parameters against lichen population data for snow patches on Rothera Point and outlying islands. Figure 5 illustrates changes over the 30-year period in temperature of the warmest month, mean annual temperature, and total number of annual positive degrees.

On the basis of our PDD calculations described above and spanning the years 1977-2007 (Figure 5), it is apparent that the years most likely to have fostered long-lived snowpatches that could have resulted in lichen kill occurred in 1978, 1981, 1994, 2000, and 2005. In all of these years PDD values fell below $40^{\circ} \mathrm{C} \mathrm{a}^{-1}$. The modulating effect of variable annual precipitation, coupled with the likelihood of different patterns of wind-drift and wind-scour, mean that snowpatches might show contrasting between-year responses to low PDD values. Snow-kill may therefore occur at some sites and not others, despite similar temperature regimes, if thicker snow is present initially. New populations of lichens will consequently become established wherever conditions are most suitable. New lichen growth within the 30 year period covered by our local meterological data, is predicted by our age model at the Rothera 2 site, which according to our age model yields an age of approximately 9 years, and at two sites on Leonie Island which yield ages of c. 24 years and c. 30 years. This suggests that their growth began around 1998, 1983, and 1977 respectively. 
Bearing the uncertainties of our age model in mind, as well as the complications associated with the influence of surface aspect and microtopography on lichen growth, these dates are surprisingly close to the three oldest of the years predicted by the PDD as those most likely to result in snowkill - 1994, 1981, and 1978. These predictions are closer to our inferred snow-kill years than the cold years 1980, 1987, and 2002 based solely on the mean annual temperatures; or the years 1978, 1994, 2000, and 2005 predicted on the basis of low maximum summer temperatures. Since PDD totals are strongly governed by summer maximums, it is no surprise that the different climate parameters predict many of the same years. Critically, however, whilst mean annual temperatures identify a cold year at 1980, and low summer temperatures pick out 1978 and 1994, only the PDD approach identifies all three cold years $(1978,1981,1994)$ that are closest to our predicted snowkill and subsequent reoccupation events. The closeness of fit between snow-kill years identified by the PDD method and the age model derived from aerial photography is therefore encouraging, and lends confidence to the use of this combined methodology.

\section{Discussion}

The construction of a preliminary lichen age-size (dating) curve for Adelaide Island (Figure 7a) has been made possible through the use of sequential aerial photographs. Given the lack of absolutely dated surfaces, the short temporal aerial photograph coverage, and the uncertainty surrounding the exact timing of snowpatch disappearance, our lichen age-size calibration 'curve' contains only 3 points (Anchorage 1, Rothera 2 and 3) and is therefore not well constrained. However, it does give an impression of maximum lichen growth rates over the last 40 years - approximately $0.8 \mathrm{~mm} / \mathrm{yr}-$ in an environment where growth calibration is extremely challenging and no current growth rate data exists. Importantly, we use a second, independent, method to establish likely snowkill years, from which maximum surface exposure ages can be inferred. Within the limits of the available local climate data, we find good agreement between PDD predictions and lichen population ages determined from our aerial photograph-derived age model.

Conversion of the calibration age-size curve, spanning only $\sim 40$ years (Fig. 7a), to a dating curve spanning the last 100 years (Fig 7b), is open to many problems - but it does at least present a framework to be tested in the future. In most environments, extrapolating optimum growth rates based on three data points in the last 40 years would be far from satisfactory, but in this environment where dated surfaces are absent we are presented with few options. However, we have taken care to make no a priori assumptions regarding the long-term growth of yellow-green Rhizocarpons in this harsh environment. Consequently, we present several scenarios in our extrapolated 'dating curve' (Figure 7b): 1) uniform optimum growth over the last 100 years (i.e. a linear age-size relationship); 2). Uniform optimum growth up to a diameter of $40 \mathrm{~mm}$, followed by a decrease in growth rate of $10 \%$; 3 ) the same scenario but with a $20 \%$ decrease; and 4 ) the same scenario but with a $30 \%$ decrease. This range of scenarios covers the most likely, expected, growth rate decline in larger (older) thalli seen in the majority of monitoring studies of Rhizocarpon growth (Bradwell and Armstrong, 2007, and references 
therein). We cannot rule out the possibility of constant (linear) growth rates persisting in even the largest thalli $(>100 \mathrm{~mm}$ ), however, as found by other studies (Matthews, 1994, Trenbirth and Matthews, this volume).

\section{Wider implications}

Despite the relatively small scale of this study it is apparent that the combination of lichen-free snowpatches and positive degree-day calculations allows a method of lichenometric calibration in an environment where normal lichen growth-rate calibration is not possible. The technique of aerial photograph analysis adopted by Fox \& Cooper (1998) to establish snowpatch decline provides a powerful mechanism for bracketing lichen growth-rate. Although there are relatively large gaps in the sequence of photography used in this study, minimum ages for primary surface exposure following snowpatch decline or disappearance can be established. The use of PDD in glacier mass balance studies is well established (e.g. Braithwaite and Olsen 1984; Singh et al. 2000), and the data presented here argue for its inclusion in lichenometric studies of lichen growth and colonisation rates, where dated surfaces are lacking. PDD data present a closer correlation to lichen snowkill events than mean annual or low summer temperatures and have allowed an independent test of lichen growth rates deduced from sequential aerial photography. Given the assumptions inherent in both of these techniques, the establishment of absolute ages for snowkill years and subsequent surface colonisation by lichen populations is not possible, however in this study the temporal uncertainty is low enough to allow greater confidence in the lichen growth calibration than would otherwise be possible.

We have shown that, on a decadal scale, lichen growth rates can be established on the Antarctic Peninsula and potentially extrapolated for use in surface dating studies spanning the last 100 years or so. This small study would be strengthened further by the collection of a larger dataset from Ryder Bay, specifically targeting more locations of recorded snowpatch disappearance since the establishment of the aerial photography programme. Although climate scenarios vary significantly over small spatial scales in glaciated environments, a relatively broad envelope of growth rates could potentially be applied to areas of similar climate on the Antarctic Peninsula. Equally, this calibration technique could be applied in areas further afield, such as Greenland, Arctic Russia, and Canada, where lichenometric calibration remains elusive.

\section{Conclusions}

1. Allied to field survey, the use of sequential historical aerial photography is successful in establishing plausible age constraints for the establishment of lichen colonisation at former snowpatch locations.

2. These age constraints can be further refined by relating lichen snowkill events to years of low positive degree-day totals $\left(<40^{\circ} \mathrm{C} \mathrm{a}^{-1}\right)$, rather than to parameters such as mean summer or annual temperature. 
3. Using this combined approach (i.e. field survey, historical aerial photographs, and calculations of annual positive degree totals) we establish a maximum subgenus Rhizocarpon growth rate of c. $0.8 \mathrm{~mm} \mathrm{a}^{-1}$ in the vicinity of Adelaide Island, Antarctic Peninsula

4. The combination of these techniques to independently verify predicted surface exposure ages represents a novel application of the lichenometric technique. We suggest that this technique may be applicable in other recently deglaciated landscapes, both around and beyond the Antarctic Peninsula, where lichen growth calibration cannot be obtained using conventional methods.

\section{Acknowledgements}

This work resulted from part of collaborative fieldwork between BGS Quaternary Earth Systems and BAS GRADES-QWAD. The authors would like to thank the staff at BAS Rothera Research Station for assistance during fieldwork, in particular John Shanklin for access to climate data, Jim Elliott, John Loines, and Base Commander Alison Dean. We are especially grateful to Micheal O' Neal and Ron Lewis Smith for informative and constructive reviews. This paper is published with the permission of the Executive Director, BGS (NERC).

Dr Nicholas Golledge, Antarctic Research Centre, Victoria University of Wellington,

P.O. Box 600, Wellington 6140, New Zealand.Email: Nick.golledge@vuw.ac.uk

Dr Jez Everest, British Geological Survey, Murchison House, West Mains Road, Edinburgh, EH9 3LA, $U K$

Dr Tom Bradwell, British Geological Survey, Murchison House, West Mains Road, Edinburgh, EH9 $3 L A, U K$

Dr Joanne Johnson, British Antarctic Survey, High Cross, Madingley Road, Cambridge, CB3 OET, UK

\section{References}

Benedict J.B., 1990: Experiments on lichen growth. I. Seasonal patterns and environmental controls. Arctic and Alpine Research 22: 244-254.

Benedict, J.B., 1991: Experiments on lichen growth. II. Effects of a seasonal snow cover. Arctic and Alpine Research, 23: 189-199.

Benedict, J.B., 2008. Experiments on lichen growth. III. The shape of the age-size curve. Arctic, Antarctic and Alpine Research, 40: 15-26. 
Bentley, M.J., Hodgson, D.A..,Smith, J.A., Cox. N.J., 2005: Relative sea level curves for the South Shetland Islands and Marguerite Bay, Antarctic Peninsula. Quaternary Science Reviews: 24: 12031216.

Beschel, R.E., 1961: Dating rock surfaces by lichen growth and its application to glaciology and physiography (lichenometry). In: G. O. Raasch (ed.): Geology of the Arctic (Proceeding of the First International Symposium on Arctic Geology), Vol. 2. University of Toronto Press, Toronto: 1044-1062.

Birkenmajer, K., 1981: Lichenometric dating of raised marine beaches at Admiralty Bay, King George Island (South Shetland Islands, West Antartica). Bulletin de l'Académie Polonaise des Sciences, Série des Sciences de la Terre, 27: 119-127.

Bradwell, T., 2001a. A new lichenometric dating curve for southeast Iceland. Geografiska Annaler 93A: 91-101.

Bradwell, T., 2001b. Glacier fluctuations, lichenometry and climatic change in Iceland. Unpublished PhD thesis, University of Edinburgh: 365pp.

Bradwell, T., 2004. Lichenometric dating in southeast Iceland: the size-frequency approach. Geografiska Annaler, 86A: 31-41.

Bradwell, T., Armstrong, R.A., 2007: Growth rates of Rhizocarpon geographicum: a review with new data from Iceland. Journal of Quatenary Science, 22: 311-320.

Braithwaite, R.J., 1980. On glacier energy balance, ablation and air temperature. Journal of Glaciology, 27: 381-391.

Braithwaite, R.J., 1984. Calculation of degree-days for glacier-climate research. Zeitschrift für Gletscherkunde und Glazialgeologie, 20: 1-8.

Braithwaite, $R$ J. and Olesen, O.B., 1984. Ice ablation in west Greenland in relation to air temperature and global radiation. Zeitschrift für Gletscherkunde und Glazialgeologie, 20: 155-168.

Cernohorsky, Z., 1977: Rhizocarpon Ram. Em. Th.Fr. In Poelt, J. and Vezda, A., (eds.)

Bestimmungschlüssel europäischer Flechten, Erganzungsheft 1, Vaduz: J.Cramer: 217-231.

Fox, A.J. and Cooper, A.P.R.,. 1998: Climate change indicators from archival aerial photography of the Antarctic Peninsula. Annals of Glaciology, 27: 636-642.

Fryday, A.M., 1997: Montane lichens in Scotland. Botanical Journal of Scotland. 49: 367-374. 
Fryday, A.M., 2001: The lichen vegetation associated with areas of late snow-lie in the Scottish Highlands. Lichenologist. 33: 121-150.

Gilbert, O.L., Fryday, A.M., Giarvini, V.J. and Coppins, B.J., 1992: The lichen vegetation of high ground in the Ben Nevis range, Scotland. Lichenologist, 24: 43-56.

Hubbard, A., Bradwell, T., Golledge, N., Hall, A., Patton, H., Sugden, D., Cooper, R. and Stoker, M., 2009: Dynamic cycles, ice streams and their impact on the extent, chronology and deglaciation of the British-Irish ice sheet. Quaternary Science Reviews, 28: 759-777.

Hooker, T.N., 1980: Factors affecting the growth of Antarctic crustose lichens. British Antarctic Survey Bulletin, 50: 1-19.

Ingólfsson, Ó. and Hjort, C., 2002: Glacial history of the Antarctic Peninsula since the Last Glacial Maximum - a synthesis. Polar Research, 21: 227-234.

Innes, J.L., 1982: Lichenometric use of an aggregated Rhizocarpon 'species'. Boreas, 11: 53-57.

Innes, J.L., 1985: Lichenometry. Progress in Physical Geography, 9: 187-254.

Kappen, L., Breuer, M., 1991: Ecological and physiological investigations in continental Antarctic cryptogams. II. Moisture relations and photosynthesis of lichens near Casey Station, Wilkes Land. Antarctic Science, 3: 273-278.

Karlen, W., Black, J.L., 2002: Estimates of lichen growth-rate in northern Sweden. Geografiska Annaler, 84A: 225-232.

Kershaw, K.A., 1985: Physiological ecology of lichens. Cambridge University Press. 293pp.

Koerner, R.M., 1980: The problem of lichen-free zones in Arctic Canada. Arctic and Alpine Research, 12: 87-94.

Levesque, E. and Svoboda, J., 1999. Vegetation re-establishment in polar "lichen-kill” landscapes: a case study of the Little Ice Age impact. Polar Research, 18: 221-228.

Lewis Smith, R.I., 1995: Colonization by lichens and the development of lichen-dominated communities in the maritime Antarctic. Lichenologist, 27: 473-483.

Mark, A.F. and Bliss, L.C., 1970: The high-alpine vegetation of Central Otago, New Zealand. New Zeland Journal of Botany, 8: 381-451. 
Noller, J.S, Locke, W.W., 2001: Lichenometry. In Quaternary Geochronology: Methods and Applications, Noller, JS et al. (eds). American Geophysical Union: Washington DC: 261-272.

Otto-Bliesner, B. L., Brady, E. C., Clauzet, G., Tomas, R., Levis, S. and Kothavala, Z., 2006: Last Glacial Maximum and Holocene Climate in CCSM3. Journal of Climate, 19: 2526-2544

Øvstedal, D.O. and Lewis Smith R.I., 2001: Lichens of Antarctica and South Georgia. A guide to their identification and ecology. Cambridge University Press. Cambridge, 405pp.

Pitman, G.T.K., 1973: A lichenometrical study of snow patch variation in the Frederikshåb District, South-West Greenland, and its implications for studies of climatic and glacial fluctuations. Meddeleser om Grønland, 192: 1-31.

Poelt, J., 1988: Rhizocarpon Ram. em. Th. Fr. Subgen. Rhizocarpon in Europe. Arctic and Alpine Research, 20: 292-298.

Pollard, D. and DeConto, R. M., 2009: Modelling West Antarctic ice sheet growth and collapse through the past five million years. Nature. doi:10.1038/nature07809.

Singh, P., Kumar, N. and Arora, M., 2000: Degree-day factors for snow and ice for Dokriani Glacier, Garhwal Himalayas. Journal of Hydrology, 235: 1-11.

Smith, A.,M., Vaughan, D.G., Doake, C.S.M. and Johnson, A.C., 1998: Surface lowering of the ice ramp at Rothera Point, Antarctic Peninsula, in response to regional climate change. Annals of Glaciology, 27: 113-118.

Runemark, H., 1956: Studies in Rhizocarpon. II. Distribution and ecology of the yellow species in Europe. Opera Botanica, 2: 1-150.

Sancho, L.G ,and Pintado, A., 2004: Evidence of high annual growth rate for lichens in the maritime Antarctic. Polar Biology, 27: 312-319.

Sancho, L.G., Allan Green, T.G. and Pintado, A., 2007: Slowest to fastest: Extreme range in lichen growth rates supports their use as an indicator of climate change in Antarctica. Flora, 202: 667-673

Solomina, O. and Calkin, P.E., 2003. Lichenometry as applied to moraines in Alaska, USA and Kamchatka, Russia. Arctic, Antarctic and Alpine Research. 35: 129-143. 
Valladares, F. and Sancho, L.G., 1995: Lichen colonization and recolonization of two recently deglaciated zones in the maritime Antarctic. Lichenologist, 27: 485-493.

\section{Table caption:}

Table 1: Matrix showing presence (white) or absence (grey) of snowpatches at each of the lichen survey sites deduced from historical aerial photography.

\section{Figure captions}

Figure 1: Map of the Antarctic Peninsula showing locations of Adelaide Island, and Ryder Bay.

Figure 2: Location map of Ryder Bay showing positions of lichen survey sites at Rothera Point, Anchorage, Leonie and Lagoon Islands.

Figure 3: Lichen sites at Rothera Point (a), Anchorage Island (b), Leonie Island (c), and Lagoon Island (d). White areas show presence of snowpatches in 2004 (derived from aerial photography).

Figure 4: Sequence of snowpatch (white) decline on Anchorage Island between 1957 and 1997 from aerial photography identified by Fox \& Cooper (1998), with the most recent aerial photography from 2004 interpreted for this study. Obvious differences in snowpatch identification are clear between Fox and Cooper (1998) and this study. Note that we have not attempted to simplify the snow distribution, and many of the minor snowpatches may have been omitted in the study by Fox and Cooper (1998). The apparent increase in snow cover between 1997 and 2004 is partly a result of this different resolution of snowpatch mapping and partly a function of heavy snowfall in the previous winter.

Figure 5: Plot of monthly climate data from BAS Rothera Research Station collected between 1977 and 2007 showing mean temperature of the warmest month, mean annual temperature, and total number of annual positive degrees.

Figure 6: Size-frequency plots of lichenometric data collected from 13 sites around Ryder Bay, Adelaide Island. Note that frequency (y-axis) is plotted on a log scale (base 10); data are in 3mm bins; and values less than the modal value have been omitted. Solid lines show simple linear regression of each dataset.

Figure 7a: (left panel) Lichen calibration plot showing sizes (max, 5-largest, 10 largest) of subgenus Rhizocarpon thalli growing in 3 abandoned snowpatch hollows of approximately known age. Lines show best-fit linear regression analyses. 
Figure 7b: (right panel) Tentative lichenometric dating curve showing extrapolation of linear age-size relationship (single largest lichen) in Figure 7a. Latter part of curve has been adjusted for assumed growth rate decline in older thalli (>40 mm), using 3 different scenarios (see text for full description). 


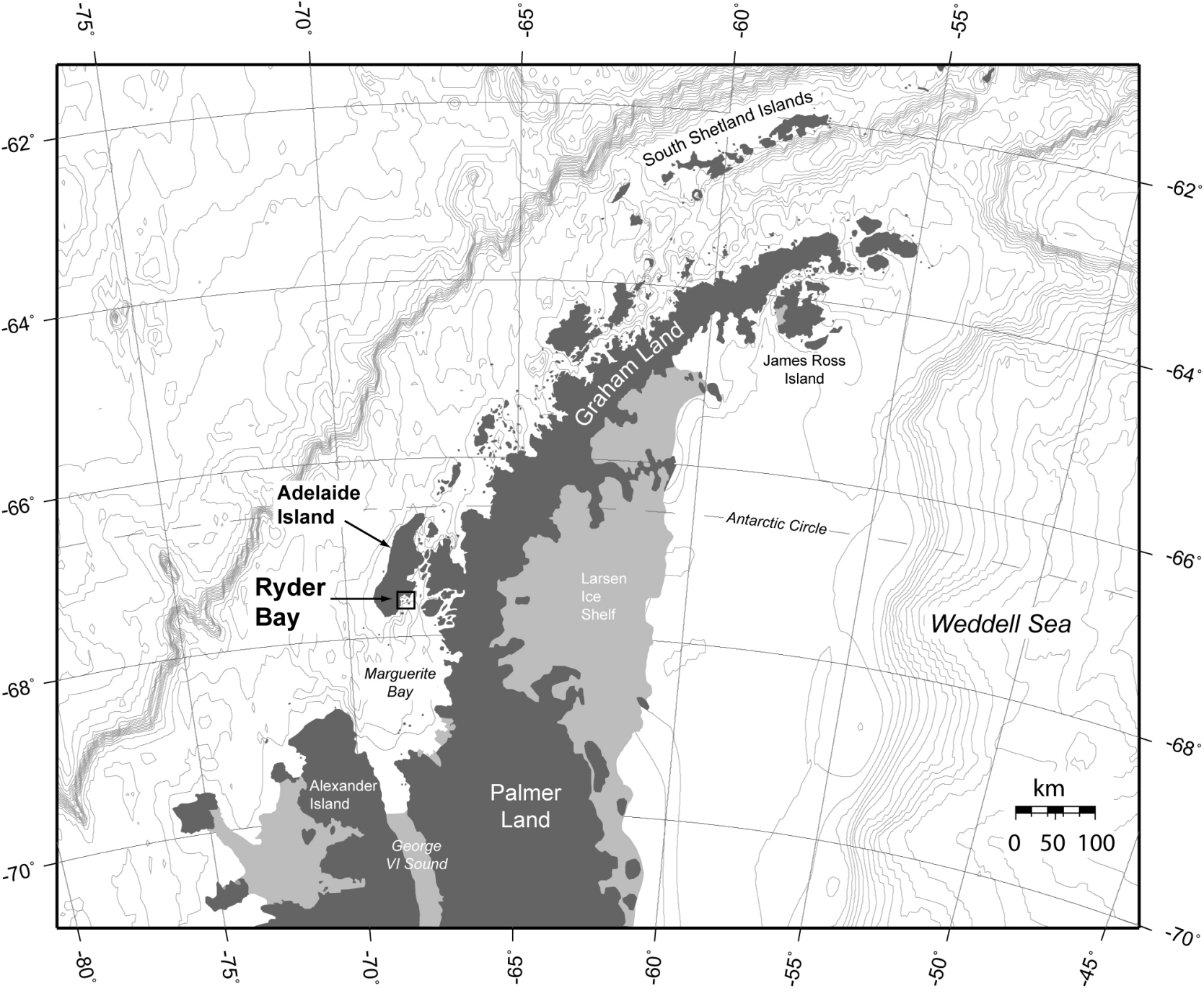


Exposed rock

Ice contour (approx position) Bathymetric contour

Sample sites (Figure 4 a-d)

Figure redrawn from BAS 25 Series, Sheet 3 'Ryder Bay' (BAS, 2006).

Contours are shown for illustration. Spot heights in metres.
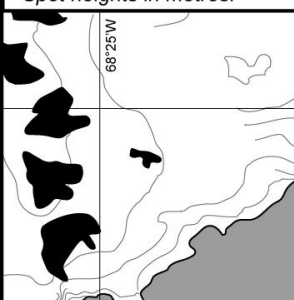

(2)
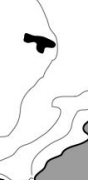
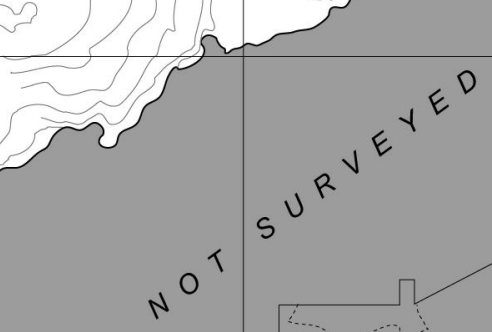

RYDER BAY

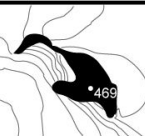

WRIGHT

PENINSULA
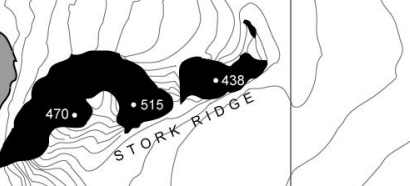

n
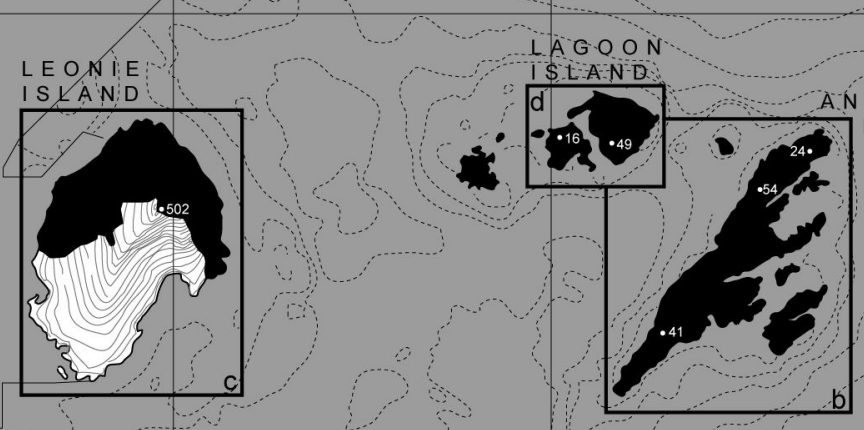

$\int_{-37}^{\text {ROTHERA }}$

SOTHE
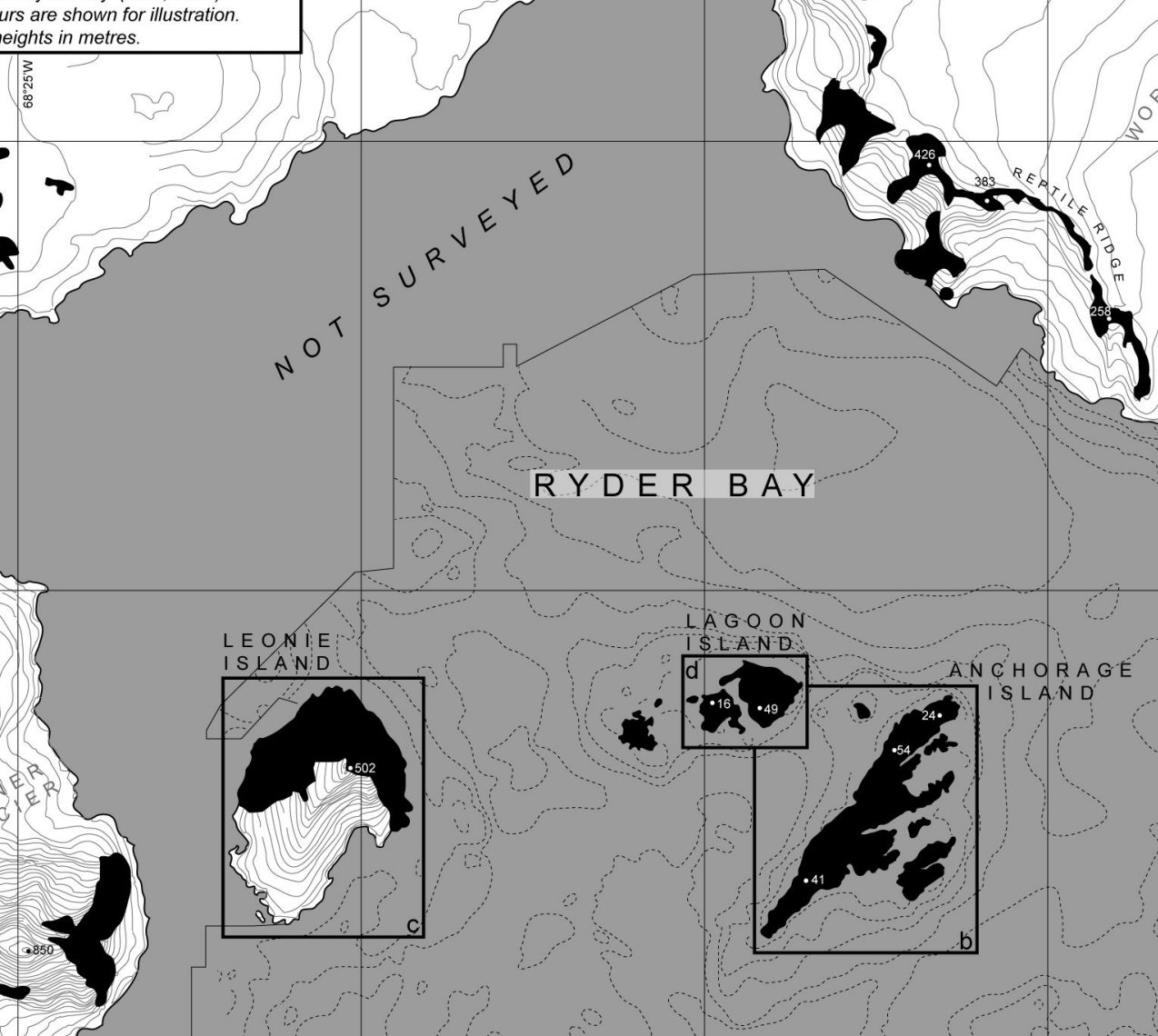

b 


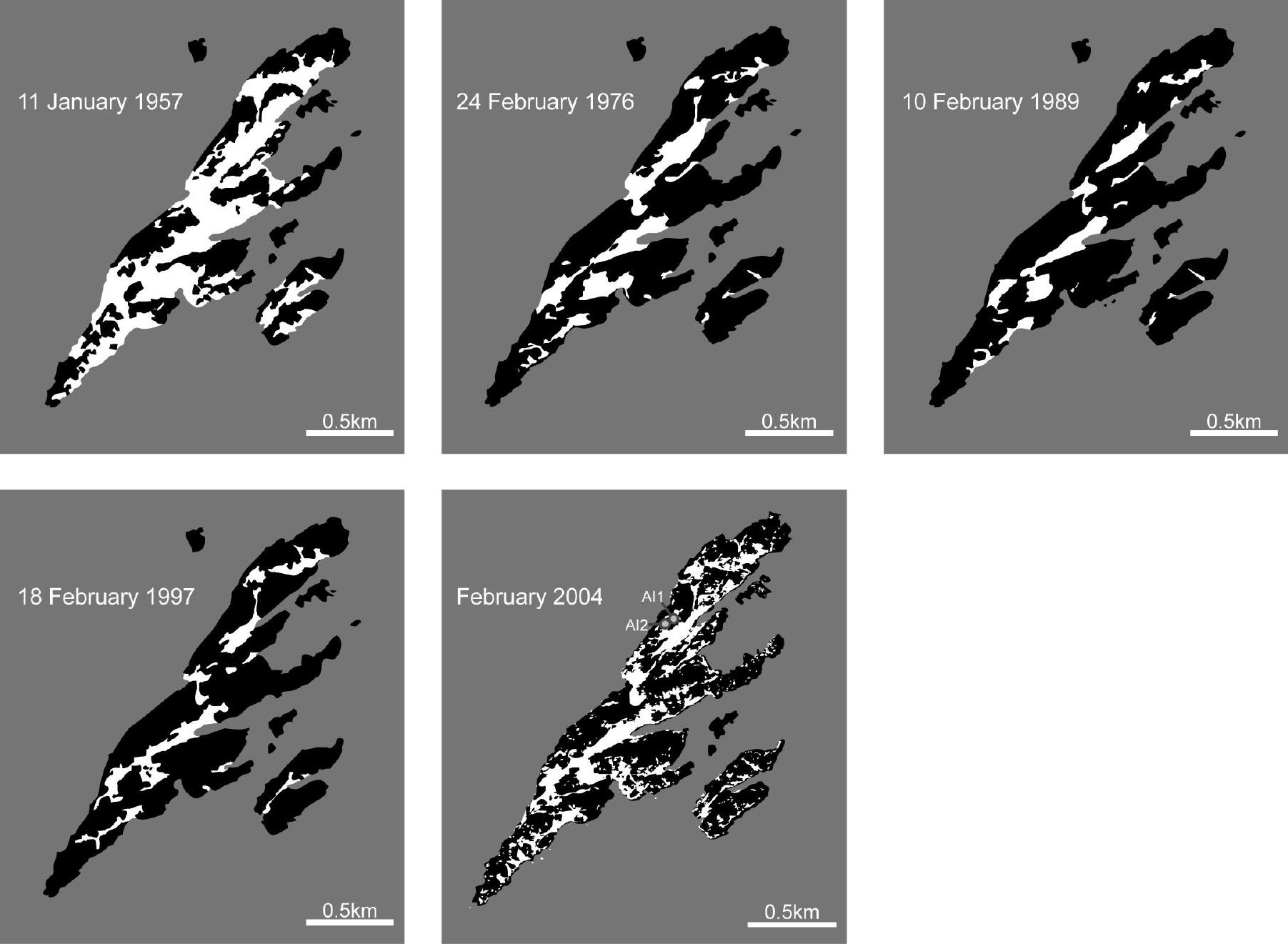


